\title{
Differences in access and patient outcomes across antiretroviral treatment clinics in the Free State province: A prospective cohort study
}

Suzanne M Ingle, Margaret May, Kerry Uebel, Venessa Timmerman, Eduan Kotze, Max Bachmann, Jonathan A C Sterne, Matthias Egger, Lara Fairall, for the International epidemiologic Databases to Evaluate AIDS Southern Africa (IeDEA-SA)

Objective. To assess differences in access to antiretroviral treatment (ART) and patient outcomes across public sector treatment facilities in the Free State province, South Africa.

Design. Prospective cohort study with retrospective database linkage. We analysed data on patients enrolled in the treatment programme across 36 facilities between May 2004 and December 2007, and assessed percentage initiating ART and percentage dead at 1 year after enrolment. Multivariable logistic regression was used to estimate associations of facility-level and patient-level characteristics with both mortality and treatment status.

Results. Of 44866 patients enrolled, 15219 initiated treatment within 1 year; 8778 died within 1 year, 7286 before accessing ART. Outcomes at 1 year varied greatly across facilities and more variability was explained by facility-level factors than by patient-level factors. The odds of starting treatment within 1 year improved over calendar time. Patients enrolled in facilities with treatment initiation available on site had higher odds of starting treatment and lower odds of death at 1 year compared with those enrolled in facilities that did not offer treatment initiation. Patients were less likely to start treatment if they were male, severely immunosuppressed (CD4 count $\leq 50$ cells $/ \mu \mathrm{l})$, or underweight $(<50 \mathrm{~kg})$. Men were also more likely to die in the first year after enrolment.

Conclusions. Although increasing numbers of patients started ART between 2004 and 2007, many patients died before accessing ART. Patient outcomes could be improved by decentralisation of treatment services, fast-tracking the most immunodeficient patients and improving access, especially for men.

S Afr Med J 2010; 100: 675-681b.
In South Africa HIV/AIDS is the top single cause of mortality, ${ }^{1-4}$ and the Free State province (FS) has the third highest HIV prevalence of the nine provinces, estimated to be $12.6 \%$ in $2008 .{ }^{5}$ There are few data on outcomes of patients from first contact with ART programmes, as most studies only report mortality from initiation of ART and ignore pre-treatment deaths. ${ }^{6}$ However, one study reported that $87 \%$ of deaths occurred in patients not on treatment. ${ }^{7}$ The Comprehensive HIV and AIDS Management (CHAM) Programme in the FS started in May 2004 as part of the scale-up of access to antiretroviral treatment (ART) in resource-limited settings. ${ }^{8}$

Department of Social Medicine, University of Bristol, UK

Suzanne M Ingle, MSc

Margaret May, $\mathrm{PhD}$

Jonathan A C Sterne, $\mathrm{PhD}$

Knowledge Translation Unit, University of Cape Town Lung Institute, University of Cape Town

Kerry Uebel, MFamMed

Venessa Timmerman, MSc

Knowledge Translation Unit, University of Cape Town Lung Institute, and Department of Medicine, University of Cape Town,

Lara Fairall, $\mathrm{PhD}$

Free State Department of Health, Bloemfontein

Eduan Kotze, $\mathrm{PhD}$

School of Medicine, Health Policy and Practice, University of East Anglia, Norwich, UK

Max Bachmann, PhD

Institute of Social and Preventive Medicine, University of Bern, Switzerland Matthias Egger, MD
Information on factors that influence whether an enrolled patient starts ART or dies before treatment, and the time spent waiting for ART, should inform policy aimed at reducing overall programme mortality. Although treatment programmes aim to start as many eligible patients as possible on treatment as quickly as possible, ${ }^{9}$ shortages of staff and facilities, time taken for adherence training and diagnosis and treatment of opportunistic infections contribute to delays in initiating ART. ${ }^{10-12}$

We report on patient outcomes, including the proportion of patients who started treatment and deaths before and on treatment, at 1 year after enrolment in the FS public treatment programme to assess management of patients. We examined differences in outcomes according to facility and patient level characteristics.

\section{Methods}

\section{Setting and patients}

All patients enrolled in the FS CHAM programme between May 2004 and December 2007 were included if a CD4 value was available. After testing HIV positive in any FS clinic, patients were referred to nurse-run assessment facilities for initial assessment of eligibility for treatment, which includes a CD4 cell count measurement. Patients with CD4 cell counts $>200$ cells $/ \mu$ l were asked to return for another assessment after $6-12$ months, or earlier if they experienced problems. ${ }^{13}$ Patients with a CD4 cell count of $\leq 200$ cells $/ \mu$, or with World Health Organization (WHO) disease stage IV (AIDS), were referred for treatment. Patients who start ART obtain monthly supplies of medication from assessment facilities and return to treatment facilities for review of their viral loads and repeat prescriptions 6-monthly. By the end of 2007, 30 clinics and 8 hospitals distributed over the 5 health districts of the FS were participating in the programme (Fig. 1). Two clinics were excluded because of delays in implementation of the electronic data collection system; of the remaining 28,17 were assessment-only facilities and 11 were combined assessment and treatment facilities. Seven of the hospitals provide treatment for patients from assessment facilities, the 8th hospital functioning as a specialist referral facility for the province. 


\section{Data collection}

Routine clinical information on patients from clinician notes on standardised forms was entered into the FS electronic medical record (EMR) system by trained data capturers and downloaded and imported into a data warehouse weekly. During this time, Meditech $\mathrm{SA}^{\mathrm{TM}}$ was gradually implemented as the EMR system across the facilities. ${ }^{14}$ As each patient has a unique identifier within Meditech, they can be tracked across facilities within the province. Mortality is ascertained by monthly linkage (using national identity numbers) with the national death register, which is estimated to capture more than $90 \%$ of adult deaths in South Africa. ${ }^{15}$ Patient demographic and clinical characteristics extracted from Meditech included gender, age, weight and CD4 count nearest to enrolment and year of enrolment into the programme. The Meditech database was linked with the National Health Laboratory Services (NHLS) database to obtain CD4 measurements to ensure that data were as complete as possible. The FS Department of Health gave permission for the data to be analysed, and the Human Research Ethics Committee of the University of Cape Town approved the protocol. No individual patient consent was deemed necessary as data were collected routinely for the CHAM programme, and no patient identifiers were included in the extracts used for analyses.

Information was obtained from programme staff on the type of facility (assessment-only clinic, treatment hospital or combined assessment and treatment clinic), location (rural/peri-urban/urban), health district, and distance between the facility and the point of care for initiation of ART (in kilometres). Data on staffing levels were obtained from the FS Human Resources database and included patient load, number of staff per 1000 patients and number of staff vacancies per 1000 patients. Staff per patient was calculated as the mean number of staff in each clinic over the period April 2005 September 2008 divided by total number of patients enrolled in that clinic.

\section{Outcomes}

Patients were followed up to 31 December 2008, and all patients therefore potentially had at least 1 year of follow-up time. The outcomes of interest were whether the patient had initiated treatment or died in the first year after enrolment.

\section{Statistical analysis}

We tabulated the characteristics of each facility and examined completeness of recording and variation in patient characteristics across facilities. We estimated median waiting times for treatment and mortality and assessed outcomes at 1 year after enrolment, by district, facility location, distance to ART initiation site and year of enrolment.

We used a mixed-effects logistic regression with random intercepts for facilities to estimate the odds of the patient starting treatment or dying within 1 year of enrolment, allowing for between-facility variability. Patient-level characteristics included in the model were gender, age, weight, CD4 count and year of enrolment. Year of enrolment was categorised as 2004/05, 2006 and 2007, as 2004 and 2005 were similar in terms of patient outcomes. Facility-level characteristics included in the model were staffing per 1000 patients, location and distance to ART initiation site. Location was categorised as rural or urban/peri-urban and included in the model as a binary variable. We fitted a sequence of four models to the data to assess the variation explained by facility- and patient-level characteristics: (i) the null model with no covariates; (ii) including patient-level characteristics only; (iii) including facility-level characteristics only; and (iv) including both facility- and patient-level characteristics. We examined the reduction in the standard deviation of the random effects distribution in each of these models.

Weight, age and CD4 count had missing values, which were imputed using the multivariate imputation by chained equations method in Stata ${ }^{\mathrm{TM}}$ assuming that data were missing at random. ${ }^{16,17}$ The imputation model consisted of all variables in the analysis model, including outcomes of interest, time to outcomes and other recorded values of pre-treatment weight and CD4. Distributions of imputed data were comparable with observed data. Data were more likely to be missing in urban facilities and facilities where treatment was available on the same site. Given that we identified predictors of missingness, it is not plausible that data were missing completely at random (MCAR). It is not possible to distinguish whether data were missing at random (MAR) or missing not at random (MNAR), but the fact that predictors of missingness tended to be clinic rather than patient characteristics makes the MAR assumption underlying the multiple imputation analyses more plausible. We analysed 25 datasets in which missing values were replaced by imputed values. Point estimates and standard errors (SEs) were calculated using Rubin's rules. ${ }^{18}$ Analyses using imputed data are presented in the main paper and analyses restricted to complete case data are presented in Appendix 2. ${ }^{19}$ All analyses were performed using Stata statistical software. ${ }^{20}$

\section{Results}

Table I shows the characteristics of each health district in the programme, and characteristics of each facility are given in Appendix 1 (Appendix 1 appears in the web version of this article only). The Motheo district includes mostly urban facilities and had the largest number of patients enrolled, while Xhariep had only rural facilities and had the smallest number of patients. Fig. 1 shows the location of each district within the province, together with the major towns in each district and locations of facilities.

Table II shows the variability in completeness of data according to district, location and distance from treatment site. Completeness of weight records was the most variable, ranging from $16.2 \%$ to $94.1 \%$ recorded; these records were most complete in urban facilities. Rural facilities had the most complete recording of CD4 counts and periurban facilities had the most complete ID recording. Facilities with ART initiation on site had the least complete CD4 records.

Between 2004 and 2007, 44866 treatment-naive patients aged 15 years or over were enrolled across the 36 facilities. As reported in Appendix 1, the median CD4 cell count at enrolment was 170 cells/ $\mu \mathrm{l}$ and ranged across facilities from 98 to 255 cells/ $\mu \mathrm{l}$. Sixty-seven per cent of patients were female (range $54-76 \%$ across facilities), mean age at enrolment was 36 years (range 33 - 38 years), and mean weight was $57.6 \mathrm{~kg}$ (range $54.7-59.7 \mathrm{~kg}$ ). Data were missing for age in 22 patients $(0.05 \%)$, for weight in 15550 patients $(34.7 \%)$ and for CD4 count in 11650 patients (26.0\%).

Table III shows patient outcomes by district, distance to ART initiation site, location and year of enrolment. Xhariep had the lowest pre-ART mortality (13.6\%) and the highest median CD4 cell count at enrolment (211 cells/ $\mu \mathrm{l})$. In contrast, Thabo Mofutsanyane had the highest pre-ART mortality (19.2\%) and the lowest median CD4 count $(151 \mathrm{cells} / \mu \mathrm{l})$. Fezile Dabi had the highest percentage initiated on ART (48.4\%), and for those who initiated, had the shortest median waiting time for treatment (1.65 months). Despite having major urban centres, Motheo district had the longest waiting times for treatment (3.70 months). Over all clinics, percentage initiated on ART ranged from $7.9 \%$ to $82.2 \%$, and mortality ranged from $8.1 \%$ to $32.8 \%$. For those who were treated, median waiting times ranged from 1 day (in a hospital setting) to 5.4 months. Of all deaths $83 \%$ occurred in patients not receiving ART. 

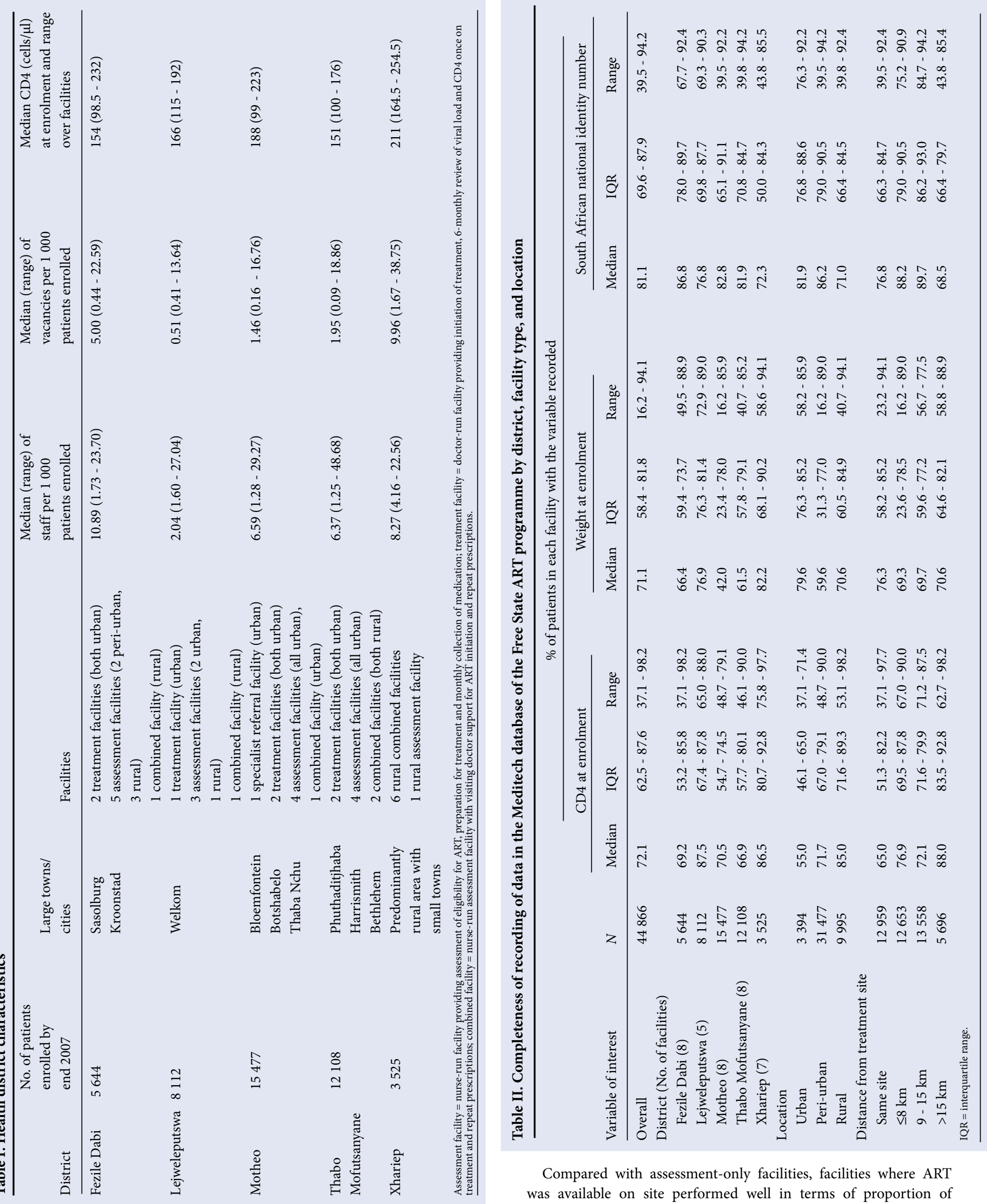

Compared with assessment-only facilities, facilities where ART was available on site performed well in terms of proportion of patients who started treatment, except for those in Xhariep district, where there was no doctor for several months. Xhariep has only 
Table III. Patient outcomes at 1 year after enrolment by district, facility type, location and year of enrolment

\begin{tabular}{|c|c|c|c|c|c|c|c|}
\hline & $N$ & $\begin{array}{l}\text { Median } \\
\text { CD4 }\end{array}$ & $N(\%)$ dead & $\begin{array}{c}N(\%) \text { dead } \\
\text { before initiating } \\
\text { treatment }\end{array}$ & $\begin{array}{l}N(\%) \\
\text { treated }\end{array}$ & $\begin{array}{l}\text { Median } \\
\text { waiting time } \\
\text { to treatment } \\
\quad(\mathrm{mo} .)\end{array}$ & $\begin{array}{c}\text { Median time } \\
\text { to death for } \\
\text { those who } \\
\text { died (mo.) }\end{array}$ \\
\hline Overall & 44866 & 170 & $8778(19.6)$ & $7286(16.2)$ & $15219(33.9)$ & 2.7 & 3.0 \\
\hline $\begin{array}{l}\text { Patients who were eligible at } \\
\text { enrolment }\end{array}$ & 19120 & 90 & $5130(26.8)$ & $4047(21.2)$ & $10194(53.3)$ & 2.98 & 3.34 \\
\hline $\begin{array}{l}\text { Patients who were not eligible at } \\
\text { enrolment }\end{array}$ & 14096 & 350 & $878(6.2)$ & $799(5.7)$ & $1704(12.1)$ & 3.54 & 5.55 \\
\hline $\begin{array}{l}\text { Patients with unrecorded CD4 } \\
\text { at enrolment }\end{array}$ & 11650 & NA & $2770(23.8)$ & $2440(20.9)$ & $3321(28.5)$ & 1.49 & 1.79 \\
\hline \multicolumn{8}{|l|}{ District } \\
\hline Fezile Dabi & 5644 & 154 & $1072(19.0)$ & $829(14.7)$ & $2731(48.4)$ & 1.65 & 2.74 \\
\hline Lejweleputswa & 8112 & 166 & $1642(20.2)$ & $1287(15.9)$ & $3210(39.6)$ & 2.74 & 3.27 \\
\hline Motheo & 15477 & 188 & $2648(17.1)$ & $2368(15.3)$ & $4084(26.4)$ & 3.70 & 3.17 \\
\hline Thabo Mofutsanyane & 12108 & 151 & $2813(23.2)$ & $2322(19.2)$ & $4191(34.6)$ & 2.38 & 2.94 \\
\hline Xhariep & 3525 & 211 & $603(17.1)$ & $480(13.6)$ & $1003(28.5)$ & 2.84 & 3.17 \\
\hline \multicolumn{8}{|l|}{ Distance from treatment site } \\
\hline Same site & 12959 & 167 & $1931(14.9)$ & $1445(11.2)$ & $5364(41.4)$ & 2.05 & 3.04 \\
\hline$\leq 8 \mathrm{~km}$ & 12653 & 160 & $2675(21.1)$ & $2136(16.9)$ & 5005 (39.6) & 2.58 & 2.98 \\
\hline $9-15 \mathrm{~km}$ & 13558 & 176 & $3107(22.9)$ & $2794(20.6)$ & $3382(24.9)$ & 3.90 & 3.31 \\
\hline$>15 \mathrm{~km}$ & 5696 & 186 & $1065(18.7)$ & $911(16.0)$ & $1468(25.8)$ & 2.61 & 2.61 \\
\hline \multicolumn{8}{|l|}{ Location } \\
\hline Urban & 3394 & 105 & $714(21.0)$ & $474(14.0)$ & $2316(68.2)$ & 1.42 & 3.04 \\
\hline Peri-urban & 31477 & 173 & $6338(20.1)$ & $5431(17.3)$ & $9702(30.8)$ & 3.07 & 3.17 \\
\hline Rural & 9995 & 188 & $1726(17.3)$ & $1381(13.8)$ & $3201(32.0)$ & 2.28 & 2.74 \\
\hline \multicolumn{8}{|l|}{ Year of enrolment } \\
\hline 2004 & 6567 & 168 & $1260(19.2)$ & $1117(17.0)$ & $1748(26.6)$ & 4.50 & 4.23 \\
\hline 2005 & 10872 & 184 & $2273(20.9)$ & 2005 (18.4) & $2708(24.9)$ & 3.83 & 3.47 \\
\hline 2006 & 12877 & 185 & $2485(19.3)$ & $2072(16.1)$ & $4259(33.1)$ & 2.68 & 2.91 \\
\hline 2007 & 14550 & 147 & $2760(19.0)$ & $2092(14.4)$ & $6504(44.7)$ & 1.95 & 2.31 \\
\hline
\end{tabular}

rural clinics, and all but one of these were combined assessment and treatment facilities served by sessional doctors. Rural facilities had higher median CD4 counts at enrolment than peri-urban or urban facilities. Treatment hospitals had lower median CD4 counts, were mostly in urban areas and served sicker patients.

Table IV shows mutually adjusted odds ratios (ORs) for the association of facility- and patient-level characteristics with $(i)$ starting treatment and (ii) death within 1 year of enrolment. As type of facility was strongly related to distance to ART initiation site, we were not able to assess the effect of both variables. Similarly, staffing levels, patient load and vacant posts were all strongly related to each other and independent effects of these variables cannot be assessed. We chose to include the distance to ART initiation site, and staffing levels, in our models. The odds of initiating treatment declined with increasing distance to ART initiation site ( $p$-value for trend $<0.001)$. Patients enrolled in facilities where ART was not available on the same site were more likely to die (OR 1.55, 95\% confidence interval (CI) 1.28 - 1.89) compared with those enrolled in facilities where ART was available on site. Men were less likely to have started treatment (OR $0.67,95 \%$ CI 0.64 - 0.71 ) and were more likely to have died within 1 year of enrolment (OR 1.30, 95\% CI 1.23 - 1.37). Compared with older patients, those aged $15-29$ years had lower odds of starting treatment (OR $0.80,95 \%$ CI 0.75 - 0.85). The odds of starting treatment increased with weight and with CD4 count up to the threshold of 200 cells/ $\mu$ l. The odds of dying within 1 year of enrolment increased with age and decreased with weight and CD4 count. Patients enrolled in 2007 were more likely to start treatment than those enrolling in earlier years.

In the complete case analyses ( $N=24510$, reported in Appendix 2 web version only), the association of staffing levels with the odds of starting treatment was attenuated and the associations of location, distance from ART initiation site and CD4 were strengthened. The association of year of enrolment with the odds of dying were strengthened. In the imputed data, weight had a median of $56.5 \mathrm{~kg}$ (interquartile range (IQR) 49.0 - 65.4), compared with $56 \mathrm{~kg}$ (IQR 49.0 - 64.0) in the complete case data. CD4 had a median of 173 cells/ $\mu \mathrm{l}(\mathrm{IQR} 80$ - 316) in imputed data compared with 170 cells/ $\mu$ l (IQR 76 - 318) in complete case data. 


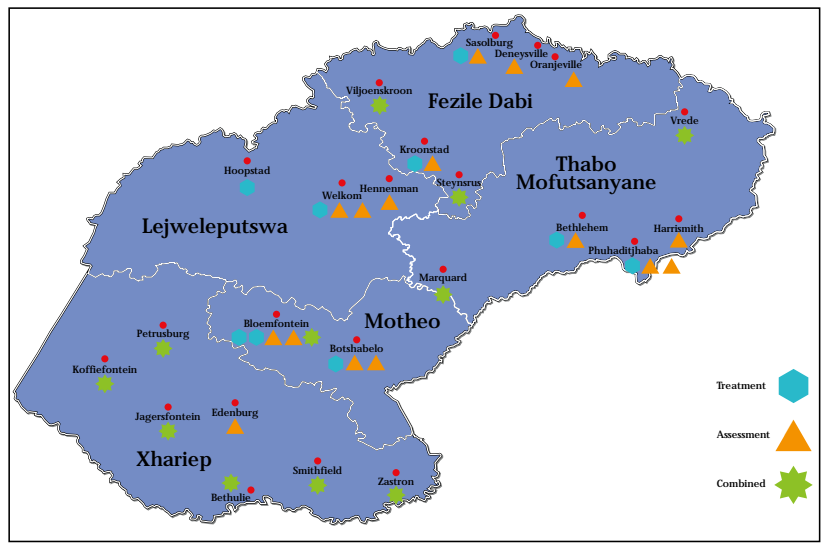

Fig. 1. Map of the Free State province ART facilities

Most of the variation across facilities in the odds of starting treatment was explained by facility- rather than patientlevel characteristics. In the null model for starting treatment, facility level standard deviation (SD) was 1.58 (95\% CI 1.33 $2.08)$; this fell to 1.46 (95\% CI 1.26 - 1.83) when patient-level characteristics were added and to 1.22 (95\% CI 1.13 - 1.38) when facility-level characteristics were added. Including both patient- and facility-level variables resulted in an SD of 1.19 (95\% CI 1.11 - 1.33).

\section{Discussion \\ Main findings}

We found a large amount of variation in odds of starting treatment across facilities and that differences in facility-level characteristics, rather than patient population, appear to drive this variation. Overall, by the end of 2008 around $34 \%$ of adults in the FS public sector programme received ART within 1 year of enrolment. The odds of starting treatment within 1 year increased between 2004 and 2007. However, large numbers of patients continue to die, most deaths (83\%) occurring in patients not receiving ART. Patients who were eligible at enrolment and started ART waited a median of almost 3 months before starting treatment. Patients were less likely to start treatment within 1 year if they were male, severely immunosuppressed (CD4 $\leq 50$ cells $/ \mu \mathrm{l})$, underweight $(<50 \mathrm{~kg})$, or sought care from a facility where ART initiation was more than $15 \mathrm{~km}$ away. Men and patients enrolled at facilities where treatment could not be initiated were also more likely to die in the first year after enrolment.

\section{Strengths and limitations}

This cohort is one of few studies to report on outcomes after enrolment in HIV care and not just from treatment initiation. ${ }^{9,21,22} \mathrm{~A}$ strength is that it is a large cohort, representative of the HIV-infected population based on routinely collected data in the FS, where there is an established data capture system in place with mechanisms to follow up specific data queries in each clinic. National identity numbers have been documented for a large proportion of patients and regular linkage with the national death register means that ascertainment of death is fairly complete, even in those lost to the programme. In an earlier study using the FS data, only $20 \%$ of all deaths were recorded in the medical records, ${ }^{7}$ which emphasises the importance of linking to the national death register.

A limitation is the large number of patients with missing weight and CD4 measurements. Although CD4 measurements were routinely taken on almost all patients, the database recorded them on only half of the patients in the cohort. This was improved to three-quarters of the patients by linkage using deterministic matching with records of blood results obtained from the NHLS.

\section{Comparison with other studies}

We are not aware of any studies that have been able to consider these outcomes across a range of facilities as we have done. Three South African studies showed high mortality rates in patients who had not initiated ART., ${ }^{91,23}$ Our finding that facilities with shorter delays had lower mortality supports their conclusions that mortality could be reduced by minimising unnecessary in-programme delays in treatment initiation. A simulation exercise ${ }^{24}$ also concluded that prioritising those with the lowest $\mathrm{CD} 4$ counts should improve outcomes. A cohort in Durban, which is well resourced by funding from non-governmental organisations, ${ }^{23}$ reported that $55 \%$ of ARTeligible patients had started treatment within 1 year of diagnosis. The FS CHAM programme appears to perform similarly, as $53 \%$ of known ART-eligible patients started treatment within 1 year of enrolment. South Africa faces unique challenges in the roll-out of public sector ART. ${ }^{25}$ While most deaths were in untreated patients, our study does not directly show the effect of ART in reducing mortality. A KwaZulu-Natal study estimates that standardised mortality rates declined with a rate ratio of 0.78 for women and 0.71 for men after scale-up of public sector ART. ${ }^{26}$

\section{Generalisability}

Our results may be generalisable to patients enrolling in care in similar settings, but cannot be applied to the population that is HIV-infected and not seeking care. We showed large differences in outcomes between facilities, which have implications for how HIV programmes are monitored. HIV prevalence is commonly monitored through sentinel surveillance, and specific research questions are often addressed using sentinel sites. ${ }^{27}$ However, sentinel sites may over-represent urban settings and not be representative of the general population. ${ }^{28}$ Care should be taken when evaluating programmes based on these data.

\section{Policy implications}

Patients who are assessed in one facility, but have to attend another to initiate ART, are disadvantaged compared with those who attend combined assessment and treatment facilities for all their care. This suggests that assessment-only facilities should be enabled to provide treatment or to ensure prompt referrals to treatment facilities. The referral process is one example of a barrier to accessing care. Drugreadiness training may be another barrier, as it can be protracted. Distance to appropriate facilities and transport costs may also be a barrier to access, particularly in rural locations. It is not always clinic practices that lead to delayed uptake of ART. In 2008, the FS had the lowest ART coverage of all South African provinces, estimated at $25.8 \%$, which is probably due to the large proportion of eligible patients who are unaware of their HIV status. ${ }^{29}$ The 2005 Human Sciences Research Council household survey found that only $36 \%$ of HIV-infected adults had ever been tested for HIV. ${ }^{30}$ Lack of awareness of HIV status contributes to the delayed uptake of ART, and campaigns should continue to target people who are unaware of their status.

Many of the sickest patients in our cohort died before they could initiate treatment, which demonstrates the need to fast-track the most at-risk patients. Fast-tracking would be easier to implement if treatment initiation were offered at assessment facilities, which is increasingly the case. This is being achieved through sessional visits by treatment facility doctors, and the STRETCH (Streamlining Tasks and Roles to Expand Treatment and Care for HIV) intervention currently under evaluation in a pragmatic randomised controlled trial in the FS. This intervention aims to optimise the use of scarce clinical skills by allowing designated nurses to re-prescribe and 


\begin{tabular}{|c|c|c|c|c|c|}
\hline & \multicolumn{5}{|c|}{ Outcome at 1 year } \\
\hline & \multicolumn{3}{|c|}{ Patient started treatment } & \multicolumn{2}{|c|}{ Patient died } \\
\hline & $N^{*}$ & OR $(95 \% \mathrm{CI})$ & $p$-value & OR $(95 \% \mathrm{CI})$ & $p$-value \\
\hline \multicolumn{6}{|c|}{ Facility-level characteristics } \\
\hline \multicolumn{6}{|c|}{ Average staff (per 1000 patients) } \\
\hline$<1.5$ & 16472 & $0.37(0.17-0.79)$ & 0.010 & $1.06(0.80-1.41)$ & 0.670 \\
\hline $1.5-2.5$ & 14274 & 1 (baseline) & & 1 (baseline) & \\
\hline$>2.5$ & 14120 & $1.22(0.61-2.43)$ & 0.580 & $1.07(0.83-1.39)$ & 0.611 \\
\hline \multicolumn{6}{|l|}{ Location } \\
\hline Rural & 9995 & $0.71(0.42-1.20)$ & 0.206 & $1.02(0.81-1.29)$ & 0.848 \\
\hline Urban/peri-urban & 34871 & 1 (baseline) & & 1 (baseline) & \\
\hline \multicolumn{6}{|c|}{ Distance to treatment initiation site } \\
\hline Same site & 12959 & 1 (baseline) & & 1 (baseline) & \\
\hline$\leq 8 \mathrm{~km}$ & 12653 & $0.67(0.35-1.30)$ & 0.239 & $1.51(1.16-1.95)$ & 0.002 \\
\hline $9-15 \mathrm{~km}$ & 13558 & $0.48(0.20-1.16)$ & 0.105 & $1.88(1.35-2.61)$ & $<0.001$ \\
\hline$>15 \mathrm{~km}$ & 5696 & $0.35(0.19-0.64)$ & 0.001 & $1.53(1.18-1.98)$ & 0.001 \\
\hline \multicolumn{6}{|c|}{ Patient-level characteristics } \\
\hline \multicolumn{6}{|c|}{ Gender } \\
\hline Male & 14953 & $0.67(0.64-0.71)$ & $<0.001$ & $1.30(1.23-1.37)$ & $<0.001$ \\
\hline Female & 29913 & 1 (baseline) & & 1 (baseline) & \\
\hline \multicolumn{6}{|l|}{ Age (years) } \\
\hline $15-29$ & 12739 & $0.80(0.75-0.85)$ & $<0.001$ & $0.72(0.67-0.77)$ & $<0.001$ \\
\hline $30-39$ & 18114 & 1 (baseline) & & 1 (baseline) & \\
\hline $40-49$ & 10234 & $1.04(0.98-1.10)$ & 0.236 & $1.07(1.00-1.14)$ & 0.036 \\
\hline$\geq 50$ & 3779 & $0.99(0.90-1.07)$ & 0.737 & $1.33(1.22-1.46)$ & $<0.001$ \\
\hline \multicolumn{6}{|l|}{ Weight (kg) } \\
\hline$<40$ & 2619 & $0.55(0.48-0.62)$ & $<0.001$ & $2.60(2.30-2.95)$ & $<0.001$ \\
\hline $40-49$ & 9500 & $0.82(0.76-0.88)$ & $<0.001$ & $1.55(1.43-1.67)$ & $<0.001$ \\
\hline $50-59$ & 14560 & 1 (baseline) & & 1 (baseline) & \\
\hline $60-79$ & 15420 & $1.05(0.99-1.12)$ & 0.118 & $0.69(0.64-0.75)$ & $<0.001$ \\
\hline$\geq 80$ & 2767 & $1.21(1.07-1.37)$ & 0.003 & $0.48(0.40-0.57)$ & $<0.001$ \\
\hline \multicolumn{6}{|c|}{ First pre-treatment $\mathrm{CD} 4$ count $(\mathrm{cell} s / \mu \mathrm{l})$} \\
\hline$\leq 25$ & 3872 & $0.73(0.67-0.80)$ & $<0.001$ & $3.75(3.41-4.12)$ & $<0.001$ \\
\hline $26-50$ & 3457 & $0.87(0.80-0.96)$ & 0.004 & $2.30(2.08-2.54)$ & $<0.001$ \\
\hline $51-100$ & 6472 & $0.95(0.89-1.03)$ & 0.208 & $1.71(1.58-1.85)$ & $<0.001$ \\
\hline $101-200$ & 11637 & 1 (baseline) & & 1 (baseline) & \\
\hline $201-350$ & 10100 & $0.24(0.22-0.26)$ & $<0.001$ & $0.54(0.50-0.60)$ & $<0.001$ \\
\hline$>350$ & 9328 & $0.05(0.05-0.06)$ & $<0.001$ & $0.25(0.22-0.28)$ & $<0.001$ \\
\hline \multicolumn{6}{|l|}{ Year of enrolment } \\
\hline $2004 / 5$ & 17439 & 1 (baseline) & & 1 (baseline) & \\
\hline 2006 & 12877 & $1.23(1.16-1.31)$ & $<0.001$ & $0.99(0.93-1.06)$ & 0.788 \\
\hline 2007 & 14550 & $1.51(1.42-1.60)$ & $<0.001$ & $0.92(0.86-0.99)$ & 0.017 \\
\hline
\end{tabular}

initiate treatment in selected adults, thereby freeing up doctors to see sicker patients. The trial seeks to provide evidence that a triaged system, where nurses are supported to prescribe ART using clearly defined clinical protocols, will improve outcomes in this setting. ${ }^{31}$

Our findings support evidence that men are disadvantaged in terms of treatment access. Postulation that women may be disadvantaged in access to health care because of familial and child-rearing duties ${ }^{32}$ resulted in many services focusing on women. Services for women are more developed through the need for antenatal and child health clinics. However, health-seeking behaviours between genders are known to differ, with men less likely to access services they need. ${ }^{33}$
Stigma, work responsibilities and homophobia might also make it more difficult for men to accept an HIV diagnosis and to seek treatment. ${ }^{33}$ Studies from similar resource-poor settings emphasise the need to encourage men to seek care earlier in HIV disease and to start ART, and suggest that health services to specifically address the needs of men should be developed. ${ }^{34-36}$

This study was funded by the National Institute of Allergy and Infectious Diseases (NIAID, grant 1 U01 AI069924-01). Suzanne Ingle was funded by a UK Medical Research Council PhD Studentship and Margaret May was funded by UK Medical Research Council grant GO600599. The FS 
ART data warehouse was developed with the help of a research grant from the International Development Research Centre, Canada (IDRC102411). The funders had no role in study design, data collection and analysis, decision to publish, or preparation of the manuscript. We also gratefully acknowledge the data capturers, nurses and doctors of the Free State programme, MediTech for assisting with data downloads to the warehouse, Terry Marshall and Sue Candy for assisting with the preparation of NHLS data, and Adrian Spoerri who helped with data linkage. We acknowledge all those who died without access to ART.

Conflict of interest. The authors declare that they have no conflict of interest.

\section{References}

1. Bradshaw D, Groenewald P, Laubscher R, et al. Initial burden of disease estimates for South Africa, 2000. S Afr Med J 2003;93(9):682-688.

2. Bradshaw D, Schneider M, Dorrington R, Bourne DE, Laubscher R. South African cause-of-death profile in transition - 1996 and future trends. S Afr Med J 2002;92(8):618-623.

3. Bradshaw D, Nannan N, Laubscher R, et al. South African National Burden of Disease Study 2000: Estimates of Provincial Mortality. Cape Town: South African Medical Research Council, 2004.

4. Dorrington RE, Johnson LF, Bradshaw D, et al. The Demographic Impact of HIV/AIDS in South Africa. National and Provincial Indicators for 2006. Cape Town: Centre for Actuarial Research, South African Medical Research Council, and Actuarial Society of South Africa, 2006.

5. Shisana O, Rehle T, Simbayi LC, et al. South African National HIV Prevalence, Incidence, Behaviour and Communication Survey 2008: A Turning Tide among Teenagers? Cape Town: HSRC Press, 2009.

6. Lawn SD, Myer L, Wood R. Efficacy of antiretroviral therapy in resource-poor settings: are outcomes comparable to those in the developed world? Clin Infect Dis 2005;41(11):1683-1684.

7. Fairall LR, Bachmann MO, Louwagie GM, et al. Effectiveness of antiretroviral treatment in a South African program: a cohort study. Arch Intern Med 2008;168(1):86-93.

8. World Health Organization. Scaling Up Antiretroviral Therapy in ResourceLimited Settings: Treatment Guidelines for a Public Health Approach. Geneva: WHO, 2004. http://www.who.int/hiv/pub/prev_care/en/arvrevision2003en.pdf (accessed 8 September 2008).

9. Lawn SD, Myer L, Orrell C, Bekker LG, Wood R. Early mortality among adults accessing a community-based antiretroviral service in South Africa: implications for programme design. AIDS 2005;19(18):2141-2148.

10. Wouters E, Van DW, Van LF, van RD, Meulemans H. Public-sector ART in the Free State Province, South Africa: Community support as an important determinant of outcome. Soc Sci Med 2009;69(8):1177-1185.

11. Hirschhorn LR, Skolnik R. Making universal access a reality - what more do we need to know? J Infect Dis 2008;197(9):1223-1225.

12. Lawn SD, Harries AD, Anglaret X, Myer L, Wood R. Early mortality among adults accessing antiretroviral treatment programmes in sub-Saharan Africa. AIDS 2008;22(15):1897-1908.

13. South African National Department of Health. National Antiretroviral Treatment Guidelines. Cape Town: Jacana, 2004. http://www.doh.gov.za/docs/facts-f.html (accessed 12 October 2009).

14. Meditech Information Technology I.2009. http://www.meditech.co.za/01000000. html (accessed 2 November 2009).

15. Statistics South Africa. Mortality and causes of death in South Africa, 2005: Findings from death notification. Statistical Release P0309 3 2007. http://www. statssa.gov.za/publications/P03093/P030932005.pdf (accessed 9 September 2008).

16. Royston P. Multiple imputation of missing values. The Stata Journal 2004;4(3): 227-241.
17. Royston P. Multiple imputation of missing values: update of ice. The Stata Journal 2005;5(4):527-536.

18. Rubin D. Multiple Imputation for Nonresponse in Surveys. New York: Wiley, 1987.

19. Sterne JA, White IR, Carlin JB, et al. Multiple imputation for missing data in epidemiological and clinical research: potential and pitfalls. BMJ 2009;338: b2393.

20. StataCorp LP. STATA Statistical Software: Release 11. College Station, TX: Stata Corp LP, 2009

21. Bassett IV, Wang B, Chetty S, et al. Loss to care and death before antiretroviral therapy in Durban, South Africa. J Acquir Immune Defic Syndr 2009;51(2):135139.

22. Thai S, Koole O, Un P, et al. Five-year experience with scaling-up access to antiretroviral treatment in an HIV care programme in Cambodia. Trop Med Int Health 2009;14(9):1048-1058.

23. Bassett IV, Regan S, Chetty S, et al. Who starts ART in Durban, South Africa?.. Not everyone who should. Presented at the 5th IAS Conference on HIV Pathogenesis, Treatment and Prevention, 19 - 22 July 2009, Cape Town. Abstract WEAD102.

24. Walensky RP, Wood R, Weinstein MC, et al. Scaling up antiretroviral therapy in South Africa: the impact of speed on survival. J Infect Dis 2008;197(9):13241332.

25. Ojikutu B, Jack C, Ramjee G. Provision of antiretroviral therapy in South Africa: unique challenges and remaining obstacles. J Infect Dis 2007;196(Suppl 3):S523S527.

26. Herbst AJ, Cooke GS, Barnighausen T, KanyKany A, Tanser F, Newell ML. Adult mortality and antiretroviral treatment roll-out in rural KwaZulu-Natal, South Africa. Bull World Health Organ 2009;87(10):754-762.

27. Boulle A, Bock P, Osler M, et al. Antiretroviral therapy and early mortality in South Africa. Bull World Health Organ 2008;86(9):678-687.

28. World Health Organization. Towards Universal Access: Scaling up Priority HIV/AIDS Interventions in the Health Sector. Geneva: WHO, 2008. http:// www.who.int/hiv/pub/Towards_Universal_Access_Report_2008.pdf (accessed 2 June 2008).

29. Adam MA, Johnson LF. Estimation of adult antiretroviral treatment coverage in South Africa. S Afr Med J 2009;99(9):661-667.

30. Shisana O, Rehle T, Simbayi LC, et al. South African National HIV Prevalence, HIV Incidence, Behaviours and Communication Survey, 2005. Cape Town: HSRC Press, 2005.

31. Fairall LR, Bachmann MO, Zwarenstein MF, et al. Streamlining tasks and roles to expand treatment and care for HIV: randomised controlled trial protocol. Trials J Infect Dis 2007;196(Suppl 3):S523-S527.

32. Box TL, Olsen M, Oddone EZ, Keitz SA. Healthcare access and utilization by patients infected with human immunodeficiency virus: does gender matter? J Womens Health (Larchmt) 2003;12(4):391-397.

33. Mane P, Aggleton P. Gender and HIV/AIDS: What do men have to do with it? Current Sociology J Infect Dis 2007;196(Suppl 3):S523-S527.

34. Braitstein P, Boulle A, Nash D, et al. Gender and the use of antiretroviral treatment in resource-constrained settings: findings from a multicenter collaboration. J Womens Health (Larchmt) 2008;17(1):47-55.

35. Cornell M, Myer L, Kaplan R, Bekker LG, Wood R. The impact of gender and income on survival and retention in a South African antiretroviral therapy programme. Trop Med Int Health 2009;14(7):722-731.

36. Keiser O, Anastos K, Schechter M, et al. Antiretroviral therapy in resourcelimited settings 1996 to 2006: patient characteristics, treatment regimens and monitoring in sub-Saharan Africa, Asia and Latin America. Trop Med Int Health 2008;13(7):870-879.

Accepted 30 April 2010. 


\section{Original Articles}

\section{Appendix 1. Facility characteristics}

\begin{tabular}{|c|c|c|c|c|c|c|c|}
\hline Clinic & $N$ & Location & $\begin{array}{l}\text { Distance to } \\
\text { treatment site } \\
\quad(\mathrm{km})\end{array}$ & $\begin{array}{l}\text { Hospital or } \\
\text { clinic }\end{array}$ & $\begin{array}{l}\text { Staff per } \\
1000 \\
\text { patients }\end{array}$ & $\begin{array}{l}\text { Vacancies } \\
\text { per } 1000 \\
\text { patients }\end{array}$ & $\begin{array}{l}\text { Median } \\
\text { CD4 at } \\
\text { enrolment }\end{array}$ \\
\hline \multicolumn{8}{|l|}{ District: Fezile Dabi } \\
\hline Boitumelo Hospital & 531 & $\mathrm{U}$ & 0 & $\mathrm{H}$ & 12.17 & 8.69 & 120 \\
\hline Lesedi CHC & 781 & $\mathrm{P}$ & 4 & $\mathrm{C}$ & 5.32 & 1.08 & 146 \\
\hline Metsimaholo Clinic & 342 & $\mathrm{R}$ & 70 & $\mathrm{C}$ & 9.61 & 5.64 & 173 \\
\hline Metsimaholo Hospital & 568 & $\mathrm{U}$ & 0 & $\mathrm{H}$ & 16.22 & 4.40 & 98.5 \\
\hline PAX CHC & 185 & $\mathrm{R}$ & 0 & $\mathrm{C}$ & 23.70 & 22.59 & 180 \\
\hline Refengkgotso Clinic & 656 & $\mathrm{R}$ & 40 & $\mathrm{C}$ & 4.46 & 3.34 & 226 \\
\hline Steynsrus Clinic & 217 & $\mathrm{R}$ & 70 & $\mathrm{C}$ & 17.69 & 5.60 & 232 \\
\hline Zamdela CHC & 2364 & $\mathrm{P}$ & 8 & $\mathrm{C}$ & 1.73 & 0.44 & 146 \\
\hline \multicolumn{8}{|l|}{ District: Lejweleputswa } \\
\hline Bongani Hospital & 448 & $\mathrm{U}$ & 0 & $\mathrm{H}$ & 23.97 & 11.43 & 115 \\
\hline Matjhabeng Clinic & 2693 & $\mathrm{P}$ & 7 & $\mathrm{C}$ & 1.80 & 0.41 & 167 \\
\hline Mohau Hospital & 328 & $\mathrm{R}$ & 0 & $\mathrm{H}$ & 27.04 & 13.64 & 118 \\
\hline Phomolong Clinic & 2035 & $\mathrm{R}$ & 30 & $\mathrm{C}$ & 2.04 & 0.46 & 192 \\
\hline Welkom Clinic & 2608 & $\mathrm{P}$ & 15 & $\mathrm{C}$ & 1.60 & 0.51 & 165 \\
\hline \multicolumn{8}{|l|}{ District: Motheo } \\
\hline Batho Clinic & 3383 & $\mathrm{P}$ & 8 & $\mathrm{C}$ & 1.38 & 0.16 & 211 \\
\hline Botshabelo Hospital & 267 & $\mathrm{P}$ & 0 & $\mathrm{H}$ & 29.27 & 16.76 & 123 \\
\hline Heidedal CHC & 4722 & $\mathrm{P}$ & 0 & $\mathrm{C}$ & 1.34 & 0.24 & 223 \\
\hline Jazzman Clinic & 394 & $\mathrm{P}$ & 8 & $\mathrm{C}$ & 10.82 & 1.87 & 121.5 \\
\hline MUCPP CHC & 4593 & $\mathrm{P}$ & 12 & $\mathrm{C}$ & 1.28 & 0.20 & 217 \\
\hline National Hospital & 794 & $\mathrm{U}$ & 0 & $\mathrm{H}$ & 11.57 & 5.31 & 99 \\
\hline Pelonomi Hospital & 277 & $\mathrm{P}$ & 0 & $\mathrm{C}$ & 9.46 & 10.74 & 173 \\
\hline Winnie Mandela Clinic & 1047 & $\mathrm{P}$ & 5 & $\mathrm{C}$ & 3.72 & 1.06 & 129 \\
\hline \multicolumn{8}{|c|}{ District: Thabo Mofutsanyane } \\
\hline Bohlokong Clinic & 1991 & $\mathrm{P}$ & 4 & $\mathrm{C}$ & 1.94 & 0.58 & 143 \\
\hline Bophelong Clinic & 339 & $\mathrm{R}$ & 0 & $\mathrm{C}$ & 13.82 & 17.08 & 176 \\
\hline Mamello CHC & 392 & $\mathrm{R}$ & 0 & $\mathrm{C}$ & 12.29 & 16.65 & 114.5 \\
\hline Manapo Hospital & 873 & $\mathrm{U}$ & 0 & $\mathrm{H}$ & 10.15 & 3.33 & 104 \\
\hline Namahadi Clinic & 3774 & $\mathrm{P}$ & 15 & $\mathrm{C}$ & 1.25 & 0.09 & 157 \\
\hline PhekolongHospital & 180 & $\mathrm{U}$ & 0 & $\mathrm{H}$ & 48.68 & 18.86 & 100 \\
\hline Tseki Clinic & 2583 & $\mathrm{P}$ & 12 & $\mathrm{C}$ & 1.98 & 0.12 & 165 \\
\hline Tsiame B Clinic & 1976 & $\mathrm{R}$ & 25 & $\mathrm{C}$ & 2.60 & 0.16 & 163 \\
\hline \multicolumn{8}{|l|}{ District: Xhariep } \\
\hline Bophelong P'burg CHC & 682 & $\mathrm{R}$ & 0 & $\mathrm{C}$ & 8.27 & 3.18 & 254.5 \\
\hline Ethembeni Clinic & 905 & $\mathrm{R}$ & 0 & $\mathrm{C}$ & 4.16 & 4.55 & 209 \\
\hline Itumeleng Clinic & 703 & $\mathrm{R}$ & 0 & $\mathrm{C}$ & 7.04 & 9.96 & 181 \\
\hline Lephoi Clinic & 236 & $\mathrm{R}$ & 0 & $\mathrm{C}$ & 15.61 & 22.64 & 238.5 \\
\hline Matlakeng Clinic & 182 & $\mathrm{R}$ & 0 & $\mathrm{C}$ & 22.56 & 38.75 & 164.5 \\
\hline Nelson Mandela Clinic & 470 & $\mathrm{R}$ & 80 & $\mathrm{C}$ & 7.09 & 1.67 & 184 \\
\hline Thembalethu Clinic & 347 & $\mathrm{R}$ & 0 & $\mathrm{C}$ & 12.89 & 18.81 & 214.5 \\
\hline Total & 44866 & & & & 4.27 & 2.26 & 170 \\
\hline $\mathrm{R}=$ rural $\mathrm{P}=$ peri-urban; $\mathrm{U}=$ urban & & & & & & & \\
\hline
\end{tabular}


Appendix 2. Adjusted associations of facility- and patient-level characteristics with patient outcomes at 1 year post enrolment: complete case analysis $(N=24510)$

\begin{tabular}{|c|c|c|c|c|c|}
\hline & \multirow[b]{3}{*}{$N$} & \multicolumn{4}{|c|}{ Outcome at 1 year } \\
\hline & & \multicolumn{2}{|c|}{ Patient started treatment } & \multicolumn{2}{|c|}{ Patient died } \\
\hline & & OR $(95 \% \mathrm{CI})$ & $p$-value & OR $(95 \% \mathrm{CI})$ & $p$-value \\
\hline \multicolumn{6}{|l|}{ Facility-level characteristics } \\
\hline \multicolumn{6}{|l|}{ Average staff (per 1000 patients) } \\
\hline$<1.5$ & 8068 & $0.41(0.17-0.97)$ & 0.044 & $0.84(0.55-1.29)$ & 0.429 \\
\hline $1.5-2.5$ & 9211 & 1 (baseline) & & 1 (baseline) & \\
\hline$>2.5$ & 7231 & $1.24(0.57-2.71)$ & 0.589 & $1.04(0.69-1.56)$ & 0.853 \\
\hline \multicolumn{6}{|l|}{ Location } \\
\hline Rural & 6245 & $0.57(0.30-1.08)$ & 0.084 & $1.30(0.90-1.86)$ & 0.158 \\
\hline Urban/peri-urban & 18265 & 1 (baseline) & & 1 (baseline) & \\
\hline Distance to treatment initiation site & & & $0.001^{*}$ & & $0.007^{*}$ \\
\hline Same site & 5513 & 1 (baseline) & & 1 (baseline) & \\
\hline$\leq 8 \mathrm{~km}$ & 7660 & $0.54(0.25-1.16)$ & 0.113 & $1.63(1.07-2.49)$ & 0.023 \\
\hline $9-15 \mathrm{~km}$ & 7803 & $0.42(0.15-1.14)$ & 0.088 & $2.10(1.26-3.52)$ & 0.005 \\
\hline$>15 \mathrm{~km}$ & 3534 & $0.35(0.18-0.71)$ & 0.004 & $1.50(1.03-2.18)$ & 0.035 \\
\hline \multicolumn{6}{|l|}{ Patient-level characteristics } \\
\hline \multicolumn{6}{|l|}{ Gender } \\
\hline Male & 7869 & $0.70(0.66-0.75)$ & $<0.001$ & $1.36(1.26-1.47)$ & $<0.001$ \\
\hline Female & 16641 & 1 (baseline) & & 1 (baseline) & \\
\hline \multicolumn{6}{|l|}{ Age (yrs) } \\
\hline $15-29$ & 6789 & $0.88(0.81-0.95)$ & 0.001 & $0.75(0.68-0.83)$ & $<0.001$ \\
\hline $30-39$ & 10045 & 1 (baseline) & & 1 (baseline) & \\
\hline $40-49$ & 5706 & $1.05(0.97-1.14)$ & 0.236 & $1.11(1.01-1.21)$ & 0.023 \\
\hline$\geq 50$ & 1970 & $1.02(0.91-1.15)$ & 0.718 & $1.42(1.25-1.61)$ & $<0.001$ \\
\hline \multicolumn{6}{|l|}{ Weight (kg) } \\
\hline$<40$ & 1116 & $0.58(0.50-0.67)$ & $<0.001$ & $3.18(2.75-3.68)$ & $<0.001$ \\
\hline $40-49$ & 5484 & $0.80(0.74-0.87)$ & $<0.001$ & $1.61(1.47-1.76)$ & $<0.001$ \\
\hline $50-59$ & 8533 & 1 (baseline) & & 1 (baseline) & \\
\hline $60-79$ & 7737 & $1.11(1.02-1.20)$ & 0.010 & $0.68(0.61-0.74)$ & $<0.001$ \\
\hline$\geq 80$ & 1640 & $1.11(0.96-1.28)$ & 0.173 & $0.53(0.43-0.66)$ & $<0.001$ \\
\hline \multicolumn{6}{|l|}{ First pre-treatment $\mathrm{CD} 4$ count $(\mathrm{cells} / \mu \mathrm{l})$} \\
\hline$\leq 25$ & 2279 & $0.57(0.51-0.63)$ & $<0.001$ & $4.29(3.84-4.80)$ & $<0.001$ \\
\hline $26-50$ & 1913 & $0.71(0.64-0.80)$ & $<0.001$ & $2.34(2.07-2.64)$ & $<0.001$ \\
\hline $51-100$ & 3451 & $0.88(0.81-0.97)$ & 0.007 & $1.75(1.58-1.94)$ & $<0.001$ \\
\hline $101-200$ & 6255 & 1 (baseline) & & 1 (baseline) & \\
\hline $201-350$ & 5356 & $0.15(0.14-0.16)$ & $<0.001$ & $0.52(0.46-0.59)$ & $<0.001$ \\
\hline$>350$ & 5256 & $0.02(0.02-0.03)$ & $<0.001$ & $0.26(0.22-0.30)$ & $<0.001$ \\
\hline \multicolumn{6}{|l|}{ Year of enrolment } \\
\hline $2004 / 5$ & 12026 & 1 (baseline) & & 1 (baseline) & \\
\hline 2006 & 7131 & $1.20(1.11-1.30)$ & $<0.001$ & $0.95(0.87-1.04)$ & 0.250 \\
\hline 2007 & 5353 & $1.76(1.61-1.92)$ & $<0.001$ & $0.85(0.76-0.94)$ & 0.002 \\
\hline
\end{tabular}

